\title{
Density Functional Theoretical Study on Redox-Dependent Hydrogen Bonding between Amide and Arylurea
}

\author{
Hyun Cho, Han Young Woo, ${ }^{\dagger \neq}$ Jong-Man Kim, and Sungu Hwang ${ }^{\mathrm{s}}{ }^{\times}$ \\ Department of Nanosystem and Nanoprocess Engineering, Pusan National Lniversity, Hirvang 627-706, Korea \\ BK21 Nano Fusion Technologv Team. Pusan National Cniversitw, Mirvang 627-706, Korea \\ -Department of Nanomaterials Engineering, Pusan National Lniversity, Mirvang 627-706, Korea \\ SDepartment of Nanomedical Engineering. Pusan National Lniversitw, Mirvang 627-706, Korea \\ E-mail: stmguápusan.ac.kr \\ Received March 17, 2009, Accepted April 22, 2009
}

Key Words: DFT, Redox-dependent lỵdrogen bonding, Arylurea. Amide

The responses of chemical systems to changes in external stimuli such as pressure, temperature. electrons, photons. and chemicals are important aspects of supramolecular chemistry. which has found applications in the sensor. molecular electronics. and molectular machine fields. to name a few.

Furthennore. hydrogen bonding is one of the most important molecular interactions in terms of these applications. Generally, the reduction of a receptor leads to the formation of a radical anion. which binds more strongly to substrates than the neutral parent molecule. We previously reported the results of a theoretical study ${ }^{3}$ on nitrobenzene/urea hydrogen bonding. in which it was found that a computational model based on density functional theory (DFT) produced an excellent correlation with experimental data. ${ }^{2}$ Recently. Woods et $a f$. described redox-switched hydrogen bonding between amide and diarylurea. ${ }^{3}$ Unlike other studies on redox-dependent hydrogen bonding. their system is based on oxidation rather than reduction. 1.4-dimethylpiperizine-2.3-dione (PZD), which has two pre-organized hydrogen acceptor atoms. can form intermolecular hydrogen bonds with both urea NH's. In the context of redox-switching. the dependence of strength of bonding upon changes in external stimuli is of great importance. We performed DFT calculations on these hydrogen bonding pairs and correlated the results with the experimental data

All QM calculations were performed using Jaguar v $\mathbf{5 . 5}$ quantum chemistry software. ${ }^{4}$ To calculate the geometries and energies of various molecules. we used the B3LYP flavor of DFT. which includes the generalized gradient approximation and a component of the exact Hartree-Fock exchange ${ }^{5-8}$ Since calculations of vibration frequencies are generally time-consuming $6-31 \mathrm{G}^{* * *}$ basis set was used to optimize the geometry and calculate the vibration frequencies. The number

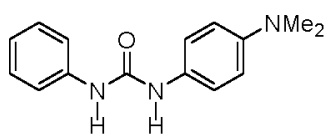

TT

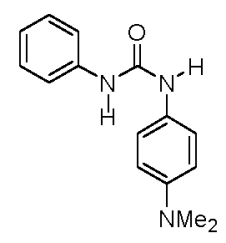

TC

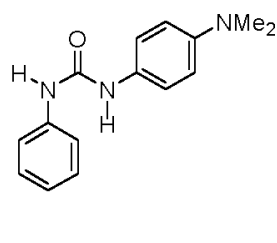

CT
Scheme 1. Conformers of a diaryl urea (PAU) of imaginary frequencies was monitored in order to check if the optimized structure of each chemical species corresponds to true minimum. Single point calculations using $6-311+\mathrm{G}^{* *}$ basis set at the structure optinized by $6 \cdot 31 \mathrm{G}^{* *}$ level were performed to check the dependence of results on the inclusion of diffuse functions. Inplicit solvation correction $\left(\mathrm{CH}_{2} \mathrm{Cl}_{2}\right)$ was taken into account using the Poisson-Boltzmann continuum model by setting the parameter $\varepsilon=9.1$ and solvent radius $=2.34 \mathrm{~A}$ at the $\mathrm{B} 3 \mathrm{LYP} / 6-3 \mathrm{IG}^{* *}$ level $^{9}$

l-phenyl-3-(4'-N,A-dimethylaminophenyl)urea. PAU, was selected as the host molecule for the present study. since it was used in the previously reported experimental study. ${ }^{3}$ The relative energies of the minima in neutral and oxidized states (both in the gas phase and in $\mathrm{CH}_{2} \mathrm{Cl}_{2}$ ) are summarized in Table 1. Since single point calculations at $B 3 L Y P / 6-31+G^{* *}$ gave very sinular trends as the B3LYP/6-31G** calculations, we only tabulated the results with single point energy corrections. In the neutral state, the energy differences between three conformers are less than $8 \mathrm{~kJ} / \mathrm{mol}$. This result was consistent with that of a recent gas-phase spectroscopic study on phenylurea. which showed that cis (C) and trans (T) conformers have similar relative energies and that they are both populated thermally at room temperature. ${ }^{101}$ Since it was reported that CC form of 1.3-diphenylurea. which has folded all cis stnucture. is much higher in relative energy than other conformers to be detected at room temperature. we did not take this form into account. ${ }^{16}$ Oxidation of PAU leads to a radical cationic state, which causes the TC conformer to be less stable than the other conformers. Solution phase energy corrections did not affect our numerical results appreciably.

Table 1. Summary of B3LYP/6-31 I++G**/B3LYP/6-31G** calculations on PAU

\begin{tabular}{|c|c|c|c|c|}
\hline & $\begin{array}{l}\Delta E_{\text {nent, gas }}{ }^{a} \\
\text { k.J.mol }^{-{ }^{-1}}\end{array}$ & 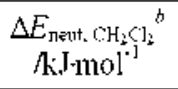 & 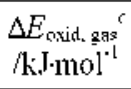 & 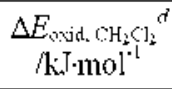 \\
\hline TT & 7.6 & 5.7 & 4.1 & 3.6 \\
\hline TC & 0.0 & 0.0 & 24.7 & 25.1 \\
\hline CT & 6.8 & 5.7 & 0.0 & 0.0 \\
\hline
\end{tabular}

"Neutral state in the gas phase: "Neutral state in $\mathrm{CH}_{2} \mathrm{Cl}_{2}$; "Oxidized state in the gas: "Oxidized state in $\mathrm{CH}_{2} \mathrm{Cl}_{2}$. 
The hydrogen bonding strengths were estimated from binding energy of the complex:

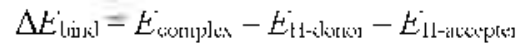

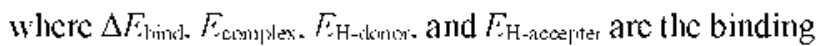
energy , the energy of complex, the energy of hydrogen bonding donor (PAU), the energy of hydrogen bonding acceptor (PZD), respectively.

Only TT conformer of PAU can form a hydrogen-bonded complex with PZD. The binding energy. $\Delta /$ turnil is $-45.1 \mathrm{~kJ}^{-\mathrm{mol}^{l}}$ relative to the TC conformer of PAU in the gas phase before oxidation. Solyation energy correction led to a slightly better binding energy of $-58.4 \mathrm{~kJ}^{\mathrm{mol}} \mathrm{mol}^{-1}$, and inclusion of temperature and entropy effects gave a marginal binding Gibbs cnergy of $-6.3 \mathrm{~kJ} \cdot \mathrm{mol}{ }^{\text {' }}$ in the neutral state. However, the oxidation of the host PAU gave much stronger hydrogen bonding. which corresponded to $\Delta E_{\mathrm{t} \text { mml }}=-120.0 \mathrm{~kJ} \cdot \mathrm{mol}^{1}$ in the gas plase. The inclusion of solvation energy y ielded a slightly better binding energy of $-133.7 \mathrm{~kJ} \cdot \mathrm{mol} \mathrm{l}^{\mathrm{S}}$. which is equivalent to a binding Gibbs energy of $-76.0 \mathrm{~kJ} \cdot \mathrm{mol}^{1}$ after thermal and entropy corrections. These binding energy values and changes are conlparable to those observed for commonly used reduction-based systems ${ }^{1.2}$ as has been previously described experimentally. "*

In Figure 1. we depict the structures of the hydrogen bonding pair before and after oxidation of PAU. The hydrogen bond distance was decreased by $0.1 \sim 0.2 \dot{A}$ after oxidation. which was also reflected by an increase in binding energy:

The TC and CT conformers of PAU can form homo- or hetero-dimers. TC/TC dimer is the most stable one before oxidation with a binding energy of $\Delta E_{\text {lukk }}=-64.4 \mathrm{~kJ} \cdot \mathrm{mol}^{\prime}$ (in $\mathrm{CH}_{2} \mathrm{Cl}_{2}$ ). which is comparable to the stability of the $\mathrm{PZD} / \mathrm{PAU}$ complex. When oxidized, the most stable dimer was found to be 1he CT/CT dimer. Binding became stronger to $\Delta F_{\text {hut }}=$ $-102.8 \mathrm{~kJ} \cdot \mathrm{mol}^{-1}$ (in $\mathrm{CH}_{2} \mathrm{Cl}_{2}$ ). which is much waker than PZD/ PAU complex in the oxidized state, however.

Figure 2 shows the optimized stmelures of PAU dimers. The lydrogen bond distances were not much changed unlike that obsen cd for the PZD/PAU casc. which reflects a smaller binding energy change in the PAU dimer.

In summary we performed DFT calculations on an amide/ urea system. A woak interaction was found between these species in the neutral state. Urea dimer formation energy is also comparable to that of the amide/urea complex. Howerer. the oxidation of the urea into its radical cation induces a strong hy drogen bonding interaction with the amide guest. a)

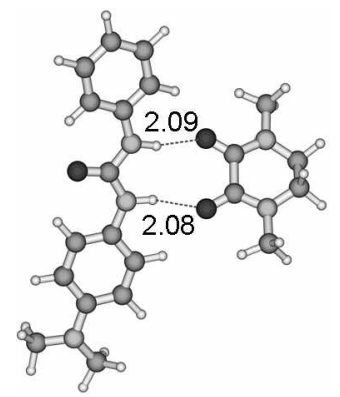

b)

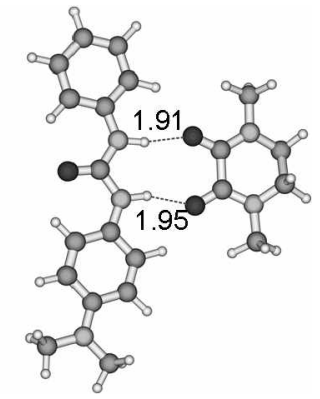

Figure 1. Optimized structures of P7D/PAU complex: a) 11eutral state and b) oxidized state.
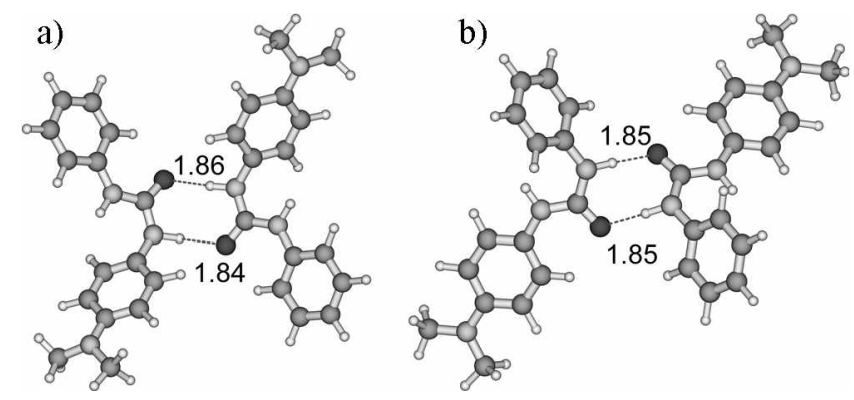

Figure 2. Optimized struclures ol PAU dimer complex: a) neutral PAU/1leutral PAU (TC/TC) and b) neutral PAU/oxidized PAU (CT/ CT).

Acknowledgments. This work was supportcd by a Pusan National University Research Grant.

\section{References}

1. Cho, Y. S.; I1wang, S. Chom. Lett. 2006, 35, 13621 .

2. Bu. J.: Lilienthal, N. D.: Woods, J. E.: Nohrden, C. E.: Hoang, K. 1.: Truong, D.: Smilh, D. K. J. in. Chem. Soc 2005, 127.6423.

3. Woods, I. L.: Gic. Y.: Smith, D). K. J. int. Chem. Soc. 2008. 130. 10070 .

4. Jaguar: y 5.5: Schrodinger: Porland, OR, USA, 1991-2003

5. Becke, A. D. Phrs Rev A $1988,38,3098$

6. I.ee, C : Yang, W: Parr, R. G. Phrs. Rev B 1988, 37, 785

7. Slater J. C. The Self-('onsistem Field for lolectles and Soldds: McGraw-Hill: New York, 1974.

8. Vosko, S. I1.: Wilk, L.: Nusair, M. Can. J. Phns, 1980. 58.1200.

9. Benites, D.: Goddard III, W. A. J. Am. Chem. Soc. 2005, 127, 12218 .

10. Limery, R.: Macleod, N. A.: Snokk, L. C.: Simons, J. P. Phys. (hem. (hem. Phns 2004, 6, 2816. 